\title{
Optimizing Daily Operation of Battery Energy Storage Systems under Real-Time Pricing Schemes
}

\author{
Juan M. Lujano-Rojas, Rodolfo Dufo-López, José L. Bernal-Agustín, Member, IEEE, \\ and João P. S. Catalão, Senior Member, IEEE
}

\begin{abstract}
Modernization of electricity networks is currently being carried out using the concept of the Smart Grid; hence, the active participation of end-user consumers and distributed generators will be allowed in order to increase system efficiency and renewable power accommodation. In this context, this paper proposes a comprehensive methodology to optimally control leadacid batteries operating under dynamic pricing schemes in both independent and aggregated ways, taking into account the effects of the charge controller operation, the variable efficiency of the power converter, and the maximum capacity of the electricity network. A genetic algorithm is used to solve the optimization problem in which the daily net cost is minimized. The effectiveness and computational efficiency of the proposed methodology is illustrated using real data from the Spanish electricity market during 2014 and 2015 in order to evaluate the effects of forecasting error of energy prices, observing an important reduction in the estimated benefit as a result of both factors: forecasting error and power system limitations.
\end{abstract}

Index Terms - Smart Grid, lead-acid battery, electricity price forecasting, battery energy storage system, real-time pricing.

\section{NOMENCLATURE}

$p$

Index for AR parameters $(p=1, \ldots, P)$.

Index for MA parameters $(q=1, \ldots, Q)$.

Index for each element of $\operatorname{HWEP}(j=1, \ldots, J)$.

Index for individuals of GA $(i=1,2, \ldots, I)$.

Index for day time $(t=1, \ldots, T)$.

Index for BESS $(n=1, \ldots, N)$.

$\begin{array}{ll}H_{j} & \text { HWEP time series }(€ / \mathrm{kWh}) . \\ \widetilde{H}_{j} & \text { Transformed HWEP. }\end{array}$

$\bar{H}_{j} \quad$ Transformed and standardized HWEP.

$E_{t} \quad$ FEP daily series $(€ / \mathrm{kWh})$.

$\tilde{E}_{t} \quad$ Transformed FEP.

$\bar{E}_{t} \quad$ Transformed and standardized FEP.

This work was supported by FEDER funds through COMPETE and by Portuguese funds through FCT, under FCOMP-01-0124-FEDER-020282 (PTDC/EEA-EEL/118519/2010), PEst-OE/EEI/LA0021/2013 and STDC/EEA-EEL/118519/2010), PEst-OE/EEI/LA0021/2013
SFRHPD/103079/2014. Moreover, the research leading to these results has received funding from the EU Seventh Framework Programme FP7/2007-2013 under grant agreement no. 309048. This work was also supported by the Ministerio de Economía y Competitividad of the Spanish Government under Project ENE2013-48517-C2-1-R.

Juan M. Lujano-Rojas is with the University of Beira Interior, Covilhã 6201001, Portugal, and also with INESC-ID, Instituto Superior Técnico, University of Lisbon, Lisbon 1049-001, Portugal (e-mail: lujano.juan@gmail.com).

Rodolfo Dufo-López and José L. Bernal-Agustín are with the University of Zaragoza, Zaragoza 50018, Spain (e-mail: rdufo@unizar.es; jlbernal@unizar.es).

João P. S. Catalão with INESC TEC and the Faculty of Engineering of the University of Porto, Porto 4200-465, Portugal, and also with C-MAST, University of Beira Interior, Covilhã 6201-001, Portugal, and also with INESC-ID, Instituto Superior Técnico, University of Lisbon, Lisbon 1049-001, Portugal (e-mail: catalao@ubi.pt). $\mu_{t}$

$F_{G}$

$F_{H}$

$F_{G}^{-1}$

$F_{H}^{-1}$

$D_{G}^{n, i}$

$\phi_{p}$

$\theta_{q}$

$S$

$\alpha$

$\chi^{2}(\alpha)$ $L$

$S O C_{\text {min }}^{n}$

$S O C_{t}^{n}$

DOD ${ }_{t}^{n}$

$C_{10}^{n}$

$\bar{C}_{10}^{n}$

$V_{n}^{t}$

$V_{o}$

$V_{D}$

$\bar{V}_{G}$

$V_{R}$

$\Delta V_{R}$

$\Delta V_{L F}$

$\Delta V_{R H}$

$V_{L F}$

$V_{R H}$

$I_{n}^{t}$

$I_{10}^{n}$

$I_{M}^{n}$

$\bar{I}_{G}$

$I_{G, t}^{n}$

$I_{L F}$

$I_{R H}$

$I_{A} / I_{B}$

$\Delta t$

$\bar{T}_{G}$

$T_{A, t}^{n}$

$C_{C}$

$C_{D}$

$C_{U}$

$C_{T}$

$M_{A}$

$M_{C}$

$M_{D}$

$R_{A}$

$R_{C}$
Hourly mean of transformed HWEP ( $€ / \mathrm{kWh})$.

CDF of a normalized Gaussian PDF.

CDF of HWEP

Inverse CDF of a normalized Gaussian PDF. Inverse CDF of HWEP.

DNC of individual $i$ for BESS $n$ at time $t(€)$.

Autoregressive parameters of ARMA model.

Moving average parameters of ARMA model.

Box-Pierce statistics

Significance level of statistical test

$\alpha$ quantile of chi-squared distribution.

Number of lags of statistical analysis.

Minimum SOC of BESS system $n$

SOC of BESS $n$ at time $t$.

DOD of BESS $n$ at time $t$.

Battery capacity of BESS $n$ in 10h (Ah/cell). Normalized capacity in respect to a $100 \mathrm{Ah}$ cell.

Battery voltage of BESS $n$ at time $t$ (V/cell). Open circuit voltage at full SOC $(2.1 \mathrm{~V} /$ cell $)$.

Variation of voltage with SOC $(0.076 \mathrm{~V} /$ cell $)$.

Normalized gassing voltage $(2.23 \mathrm{~V} /$ cell $)$.

Regulation battery voltage $(2.23 \mathrm{~V} /$ cell $)$.

Estimation error of BM (V/cell).

Error of BM at left side of interval (V/cell).

Error of BM at right side of interval (V/cell).

Voltage at left side of interval (V/cell).

Voltage at right side of interval (V/cell).

Battery current of BESS $n$ at time $t$ (A/cell).

Battery current of BESS $n$ in 10h (A/cell).

Maximum battery current of BESS $n$ (A/cell).

Normalized gassing current $(20 \mathrm{~mA} /$ cell $)$.

Gassing current of BESS $n$ at time $t$ (A/cell).

Current at left side of search interval (A/cell).

Current at right side of search interval (A/cell).

Intermediate BM variables (A/cell).

Value of a time step (1h).

Normalized gassing temperature (298 K).

Ambient temperature of BESS $n$ at time $t(\mathrm{~K})$.

Normalized battery capacity (1.001).

Normalized battery capacity (1.75).

Voltage factor of gassing process $\left(11 \mathrm{~V}^{-1}\right)$.

Temperature factor of gassing $\left(0.06 \mathrm{~V}^{-1}\right)$.

Parameter of converter (0.078815).

Parameter charge-transfer process $(0.888)$.

Parameter charge-transfer process (0.0464).

Parameter of converter (0.015784).

Charging internal resistance $(0.42 \Omega \mathrm{Ah})$. 
$R_{D} \quad$ Discharging internal resistance $(0.699 \Omega \mathrm{Ah})$.

$N_{s}^{n} \quad$ Number of cells in serial of BESS $n$.

$N_{p}^{n} \quad$ Number of cells in parallel of BESS $n$.

$P_{B, t}^{n} \quad$ Power from/to LAB $n$ at time $t(\mathrm{~kW})$.

$P_{E, t}^{n} \quad$ Power from/to BESS $n$ at time $t(\mathrm{~kW})$.

$P_{C}^{n} \quad$ Rated power of converter of BESS $n(\mathrm{~kW})$.

$\eta_{C}^{n} \quad$ Converter efficiency of BESS $n$.

$P_{A, t}^{n} \quad$ Power of BESS aggregator $n$ at time $t(\mathrm{~kW})$.

$P_{r}^{n} \quad$ Reduced power setting per cell (W/cell).

$P_{G, t}^{n, i} \quad$ Power of individual $i$ for BESS $n$ at time $t$

$P_{G, t}^{n, i} \quad(\mathrm{~kW})$.

$\bar{P}_{G, t}^{n} \quad$ Optimal scheduling of BESS $n$ at time $t(\mathrm{~kW})$.

$B \quad$ Population of GA.

I Population size of GA.

$G \quad$ Number of generation of GA.

$X \quad$ Crossover rate of GA (\%).

$M \quad$ Mutation rate of GA (\%).

$\vec{b}_{i} \quad$ Individual $i$ of GA.

$b_{t}^{i} \quad$ Control action for individual $i$ at time $t$.

$f_{i}^{n} \quad$ Fitness of individual $i$ for BESS $n$.

$S_{L} \quad$ Maximum capacity of SG $(\mathrm{kW})$.

$\Delta S_{L} \quad$ Overload of SG $(\mathrm{kW})$.

$W_{n} \quad$ Weighting factor of BESS $n$.

$P_{M}^{n} \quad$ Maximum power per cell of BESS $n$ (W/cell).

$P_{r}^{n} \quad$ Reduced power per cell of BESS $n$ (W/cell).

$k$ Iterations of BM $(k=1, \ldots, K)$.

\section{INTRODUCTION}

A $\mathrm{S}$ a result of constant industrialization, technological development, and the economic growth or many countries, social awareness of environmental problems has increased the incorporation of renewable energies for power generation. However, technical limitations in transmission and distribution networks, the variability of renewable power sources such as wind and solar photovoltaic (PV) energies, people's behaviors, and energy consumption patterns have made it difficult to integrate and accommodate these sources. In this scenario, the integration of storage technologies has emerged as an option to expedite energy consumption from renewable sources by increasing the flexibility of the power system. Topics related to the Battery Energy Storage System (BESS) operation need to be considered to guarantee the feasible integration of a BESS with renewable and conventional generation sources currently being operated; this includes the estimation of storage capacity and its corresponding duration - or, in other words, the estimation of the available power and discharge time - and the incorporation of the transmission and distribution capacity [1]. With the conceptual evolution of traditional distribution systems toward the Smart Grid (SG) and, consequently, the implementation of dynamic pricing schemes such as Time of Use (TOU) and Real Time (RT) programs, incorporating a BESS at the residential level would improve power system performance; however, some specific techno-economic conditions are still required. According to recent studies, under TOU [2] and RT [3] programs, the acquisition costs of a BESS have to be reduced, its lifetime in terms of the number of cycles should be increased, and the difference between the maximum and minimum daily electricity prices should be increased in order to compensate capital and operational costs. In this regard, governmental policies and incentives are very important. A representative example is the Self-Generation Incentive Program [4] administrated by the California Public Utilities Commission. This program aims to incentivize electricity production from wind turbines, fuel cells, combined heat and power generation systems, and advanced energy storage systems (ESSs).

The optimal operation of ESSs, considering an RT pricing tariff, becomes particularly relevant for the successful adoption and integration of these technologies; this problem has been analyzed from different perspectives by several authors, and the results obtained from their efforts can be found in the specialized literature.

In [5], historical data on the electricity price forecasting of the Ontario market are carefully analyzed in terms of forecasting error and its impact on the profitability of a Compressed Air Energy Storage (CAES) system operating under dynamic pricing. This analysis is carried out by solving a Mixed-Integer Linear Programming (MILP) problem, in which the economic revenue obtained from the operation of the CAES system is maximized and consideration is given to its corresponding operational constraints. Then, in order to mitigate the negative effects of forecasting error, the objective function is calibrated by taking into account the magnitude of the prediction error that occurred during the last hours or days.

In [6], a scheduling procedure to improve renewable power accommodation by simultaneously reducing power curtailment and forecasting error was presented and analyzed through mathematical simulations. The method consists of two main steps, a scheduling process on a daily basis and real-time control. During the scheduling process, an optimal day-ahead profile of the joint system (renewable generator and ESS) is determined by considering the energy actually stored on the ESS, renewable power, and load demand predictions. During the real-time control process, the power of the joint system is dispatched in order to follow the optimal generation profile determined in the scheduling procedure, taking into account all the operational constraints of the joint system. According to the obtained results, this control strategy offers an important reduction in forecasting error even when ESSs of moderate capacity are considered.

In [7], a control strategy for the operation of an energy system provided with PV generation and a BESS installed at the residential level was presented considering three price periods (off-peak period, low-peak period, and high-peak period). This approach uses predictions of PV generation and load demand, which are incorporated into a hierarchical control system composed of two main levels, a global one and a local one. The global level optimally determines the condition (charging or discharging) of BESSs in the future based on cost minimization and peak shaving, while the local level reduces the impact of renewable power and load demand forecasting errors. In a similar way, a control algorithm that analyzes BESS management from an intra-daily perspective was developed in [8]. The control strategy aims to minimize the total electricity cost by solving the corresponding optimal storage control problem using a piecewise linear approximation of the objective function embedded in a Linear 
Programming (LP) problem. In order to guarantee the minimal storage requirements of the BESS under analysis, a reinforcement learning technique is incorporated.

In [9], the concept of an aggregator for PV-BESSs installed at the residential level, including physical and communication infrastructures, was developed. The aggregator is assumed to have a centralized operation mode, where its optimal behavior is determined through the solution of a MILP problem carried out in two steps. In the first step, integer variables related to Electric Vehicle (EV) charging are found by using a continuous relaxation method; in the second step, the optimal values for the rest of the variables are determined by solving an LP problem. Besides this, the forecasting error of electricity prices, PV generation, and EV charging profile are handled by using Model Predictive Control (MPC).

In [10], cooperative-driven, distributed MPC was proposed as a control method for BESSs in order to perform voltage regulation in distribution networks. This method is based on the solution of an optimization problem in which the variations on the control variables are minimized. According to the reported results from the analysis of a typical rural distribution network provided with renewable generation under over-voltage, low-voltage, and voltage-drop conditions, the presented approach offers similar results to those obtained from the implementation of the centralized MPC method.

The researchers in [11] deeply analyzed the behavior of a typical energy system composed of a conventional generator, several base and flexible loads, several subsystems composed of renewable generators and ESSs, and several external electricity markets. Optimal operation is mathematically formulated in order to minimize the system cost on a longterm basis through the manipulation of controllable energy sources, load demand, and ESSs, taking into account the uncertainty introduced by renewable power sources. This optimization problem is solved using the Lyapunov optimization technique combined with a relaxation procedure.

Considering the energy policy in which residential consumers are only able to buy electricity from the SG, a BESS control strategy based on a Dynamic Programming (DP) approach was developed in [12]. The presented methodology considers specific discrete states for charging and discharging conditions; in order to avoid those solutions that could negatively influence a BESS's lifetime, a backward tracing procedure is introduced. Finally, corrective control actions are taken during real-time operation so that the effects of forecasting error of electricity prices, load demand, and renewable generation are mitigated.

In [13], the implementation of a DP approach in two temporal scales was proposed for the control of energy systems with a BESS, typical residential loads, and renewable power generation under dynamic pricing. The presented method consists of the application of a DP optimization method on the macro- and microscales. A macroscale DP method is applied by considering the forecasting information on a daily basis; hence, a first approximation of the optimal scheduling is obtained in terms of the State of Charge (SOC) of the BESS. Then, the microscale DP method is applied using forecasting information with a shorter prediction horizon (three-hour-ahead predictions) in order to guarantee the optimal behavior expressed in terms of the SOC obtained in the previous step; in this way, the impact of the forecasting error can be mitigated.

In [14], a strategy based on a DP approach for the control of a Lead-Acid Battery (LAB) was developed; the DP approach was applied by considering discrete states of the SOC with the objective of maximizing the economic benefits from the daily operation of the BESS, taking into account the Battery Wear Cost (BWC), full filling of certain operational constraints related to SOC limits, and charging and discharging rates. Lifetime reduction of the BESS related to operation at partial SOC is incorporated as an increment in system costs; this is known as the Cost of Lifetime Losses estimation.

Assuming that residential consumers are only able to buy electricity from the SG, the rated power of the BESS is applied during charging and discharging periods of equal duration, as well as the representation of the SOC by a number of limited discrete states; in [15], a control strategy was developed for the optimal operation of a BESS on semi-daily and daily bases, defined according to the Moving Average of $\mathrm{RT}$ pricing forecasting.

In [16], the operation of BESSs installed over distribution networks was analyzed and their capabilities to mitigate voltage fluctuations were studied through numerical simulations. Assuming that the Distribution Network Operator (DNO) is able to give subsidies to commercial customers to promote the local installation of ESSs, the storage capacity at the customer level is determined by taking into account the aforementioned subsidies and high-voltage distribution network constraints, specifically those related to voltage variations. This approach allows us to consider the viewpoint of the DNO and commercial customers at the same time.

In [17], a methodology based on the implementation of hyper-heuristic algorithms was proposed. Considering the maximum possible power to be supplied, 26 heuristic levelsfrom no discharging condition to totally discharging condition-were defined; then, the corresponding fitness function and heuristic operators were applied in order to determine a profitable discharging scheduling for the ESS under analysis. The proposed methodology was illustrated by considering a Vented LAB, whose dynamic behavior regarding the capacity as a function of discharge time and charging power limitations were incorporated by using general-purpose information normalized with respect to the capacity in $240 \mathrm{~h}$.

In [18], an optimization algorithm for the optimal operation of ESSs based on power-to-heat conversion was presented. The fundamental idea consists of charging ESSs during lowprice periods, taking into account the amount of energy stored and the maximum charging power allowed at each time step. Initially, a mathematical formulation neglecting energy losses is developed; then, two optimization models considering energy losses as a constant and variable value are derived.

In [19], a management model for BESSs integrated in a smart community was analyzed by developing an auction process by which each owner of a BESS, customers, and building managers are related to each other through a market environment. The storage capacity and its corresponding auction price are optimally determined by means of a noncooperative Stackelberg game established between the owners of BESSs and building managers acting as auctioneers. 
In this way, the incentive compatibility and individual rationality are compensated at the equilibrium point of the Stackelberg game.

A control strategy based on the theory of pseudo-SOC was developed in [20] to incorporate ancillary services provided by distributed generators; the algorithm takes information from the operation of the energy system, such as an SOC, as well as the amount of PV generation, in order to estimate the real-time operating conditions in terms of voltage and determine the optimal operating strategy of the BESS.

In [21], several resources, strategies, and operational problems such as renewable power generation, peak-load shaving, power-curve smoothing, and voltage regulation have been integrated in a control technique based on minimizing total costs, by which the costs related to the peak-load shaving activity are weighted according to the amount of power flowing through the distribution transformer. Using this formulation, the corresponding optimization problem is solved by means of a sequential quadratic programming approach.

Among ESS technologies, advanced LABs (specifically Valve-Regulated LABs) have been installed and analyzed in terms of their technical design and performance in order to gain experience and knowledge of their operational problems, such as thermal management issues and cell behavior [22]. According to the Global Energy Storage Database [23], BESSs based on LABs are currently being investigated to improve the accommodation of renewable generation, manage and reduce electricity bills, shift energy time, enhance power supply and spinning reserve, regulate frequency, improve system reliability and the power quality of commercial consumers, and enhance power-system ramping capabilities, as well as renewables' capacity firming. The typical rated power of these installations is between $2 \mathrm{~kW}$ and $36 \mathrm{MW}$. They are currently being operated in several countries, including Australia, Cape Verde, Germany, India, Ireland, Japan, Kenya, South Korea, Madagascar, New Zealand, South Africa, Taiwan, the United Kingdom, and the United States, among others, and administrated by cooperatives and independent investors, as well as by federal and municipal institutions.

Although many of the existing methodologies for the optimal control of a LAB, when it is operating under dynamic pricing, offer reasonable solutions from a mathematical perspective, many of them are not capable of incorporating the nonlinear behavior of the LAB, such as the gassing phenomena of electrochemical processes, the voltage regulation of the charge controller, and the variable efficiency of the bidirectional converter. On the one hand, during the charging process of a typical LAB, the charge controller reduces the corresponding current in order to mitigate the effects of the gassing phenomenon by maintaining the battery voltage at a constant value (frequently $2.23 \mathrm{~V} /$ cell); as a consequence, the amount of power purchased from the grid is gradually reduced in a nonlinear way. On the other hand, the efficiency of the power converter has nonlinear behavior: When a low amount of power (compared to its rated capacity) is transmitted through the converter, the conversion efficiency is very low; however, this efficiency increases with the transmitted power. This fact could influence the power trading between a LAB and the SG and, consequently, the economic performance of the system.

In this paper the optimal operation of LABs, including all these issues, is analyzed from the perspective of an independent BESS and an aggregator of it. As an optimization tool, an integer-coded Genetic Algorithm (GA) is used, considering charging, discharging, and no-power transactions between the BESS and the SG. This tool is used to analyze the influence of the electricity price forecasting error and the limitations of the SG (in terms of the maximum power allowed to be taken from or supplied to the SG by the BESS aggregator) on the economic benefit obtained from the optimal BESS operation. The rest of the paper is organized as follows: Section III describes the proposed approach, including the electricity price forecasting process, LAB model, and optimization technique. Section IV presents the case study analyzed in order to illustrate the proposed approach. Finally, the main conclusions are presented and discussed in section $\mathrm{V}$.

\section{PROPOSED APPROACH}

In Fig. 1, the general structure of an independent BESS connected to the SG under an RT pricing environment is described. The SG is represented by the power system with two main communication channels: one to the power flow (Power in Fig. 1) in a bidirectional way and another one to the data flow (Data in Fig. 1) specifically for the transmission of electricity prices in real time. A Smart Meter (SM) has the role of interfacing between the Battery Management System (BMS) and the SG. The SM receives electricity prices and measures the power transaction from or to the SG and communicates this information to the BMS; then, all the collected data related to electricity prices are used to create a database of Historical Wholesale Electricity Price (HWEP) required to carry out the Forecasting Electricity Price (FEP) on a daily basis. Besides storing the HWEP database, the BMS is continuously monitoring the operating conditions of the LAB in terms of battery voltage, current, and SOC (Voltage/Current/State of Charge in Fig. 1), and it is able to store the parameters of the LAB model, which is very important information to be jointly used with the FEP to determine the optimal LAB scheduling through an optimization analysis (using an integer-coded GA). This optimization analysis is supposed to be implemented in the BMS; hence, this unit could be conceptually understood as an embedded system, which receives the FEP and the operating conditions of the LAB in order to estimate its optimal management during the following day. The optimal LAB schedule consists of when the BESS should be charged or discharged, including the corresponding charging and discharging power, in order to maximize the economic benefit obtained from the power transaction between the SG and the BESS; this schedule is implemented by sending a control signal from the BMS to the Charge Controller (Charging/Discharging in Fig. 1). In brief, in the process required to determine and execute the optimal schedule for the BESS, it is necessary to carry out three main procedures: electricity price forecasting, optimization analysis and LAB simulation, and scheduling implementation. In the following subsections, these procedures are carefully described and discussed. 


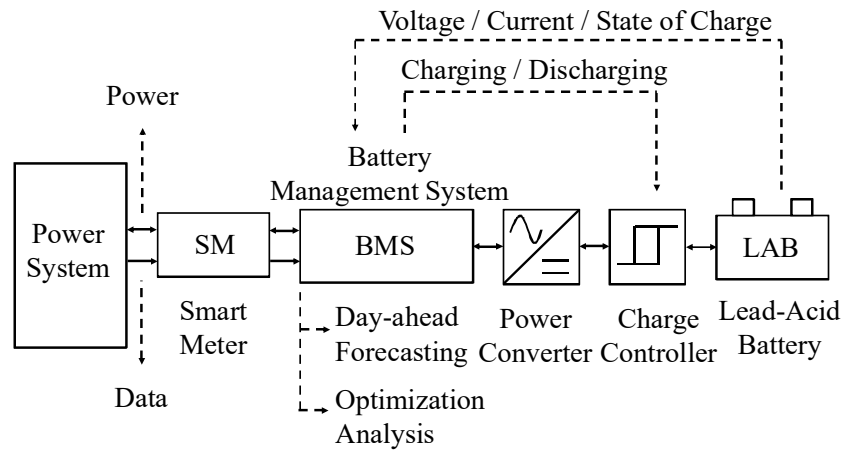

Fig. 1. General description of an independent BESS connected to SG.

\section{A. Day-Ahead Electricity Price Forecasting}

In order to determine the optimal scheduling of the BESS that would maximize the economic benefit of the power transaction between the BESS and the SG, an FEP is absolutely required. In this paper, a time-series analysis based on an Autoregressive Moving Average (ARMA) model has been used.

The ARMA model is implemented in the BMS and requires the estimation of autoregressive and moving-average coefficients. To carry out this task, the HWEP time series needs to be manipulated to have the characteristics of a normalized Gaussian probability distribution function (PDF). This transformation process [24] is briefly described in (1), where each element of the HWEP $\left(H_{j} \ngtr j=1, \ldots, J\right)$ is evaluated on its own discrete Cumulative Distribution Function $(\mathrm{CDF})\left(F_{H}\right)$, resulting in a new time series with a uniform PDF. This time series is consequently evaluated (in an inverse way) on the CDF of a discrete normalized Gaussian PDF $\left(F_{G}^{-1}\right)$, which is obtained from the discretization methodology presented in [25].

This procedure results in the time series $\left(\widetilde{H}_{j} \ngtr j=1, \ldots, J\right)$, which has a diurnal non-stationarity that is directly related to the pattern of electricity usage. This is removed by subtracting the hourly mean $\left(\mu_{t} \ngtr t=1, \ldots, 24\right)$, as shown in (2). Then, the ARMA model of (3) [26] is fitted by means of the Bayesian Information Criterion (BIC) [27] or the Akaike Information Criterion (AIC) [28] and is statistically verified through the Ljung-Box method [29], which compares the value of a chi-square distribution $\left(\chi^{2}\right)$ with the significance level $\alpha$ and the $L-P-Q$ degree of freedom with the value of statistic $(S)$.

$$
\begin{gathered}
\widetilde{H}_{j}=F_{G}^{-1}\left(F_{H}\left(H_{j}\right)\right) \ngtr j=1, \ldots, J ; \\
\bar{H}_{j}=\widetilde{H}_{j}-\mu_{t} \ngtr j=1, \ldots, J \ngtr t=1, \ldots, T ; \\
\bar{H}_{j}=\sum_{p=1}^{P} \phi_{p} \bar{H}_{j-p}+\sum_{q=1}^{Q} \theta_{q} \varepsilon_{j-q} \ngtr j=1, \ldots, J .
\end{gathered}
$$

Day-ahead forecasting is carried out by evaluating the ARMA model previously estimated, as shown in (4), and by completing the transformation process as presented in (5) and (6).

$$
\begin{gathered}
\bar{E}_{t}=\sum_{p=1}^{P} \phi_{p} \bar{E}_{t-p}+\sum_{q=1}^{Q} \theta_{q} \varepsilon_{t-q} \ngtr t=1, \ldots, T ; \\
\tilde{E}_{t}=\bar{E}_{t}+\mu_{t} \ngtr t=1, \ldots, T ; \\
E_{t}=F_{H}^{-1}\left(F_{G}\left(\tilde{E}_{t}\right)\right) \ngtr t=1, \ldots, T .
\end{gathered}
$$

In brief, the entire process for day-ahead price forecasting starts by creating the discretized CDF of the HWEP and the Gaussian CDF; then, each element of the HWEP time series is evaluated on its own CDF, and it is evaluated again on the inverse Gaussian CDF. When all elements have been evaluated, the hourly average profile is subtracted; thus, a normalized time series is obtained. The next step consists of determining the order and coefficients of the ARMA model. Once this step has been concluded, the estimated model is sequentially evaluated from $t=1$ until $t=T$, the hourly average profile is added, and the obtained result is transformed from a discretized Gaussian PDF to the PDF of the HWEP by evaluating each of these values (those $T$ values resulting from the evaluation of the ARMA model previously performed) on the discretized Gaussian CDF and again on the inverse CDF of the HWEP.

\section{B. Lead-Acid Battery Model and Simulation}

The general-purpose LAB model presented in [30] is used in this work due to its ability to represent physic-chemical processes. As the model developed in this work could be used to optimize the operation of a LAB aggregator, the mathematical model is expressed in terms of an independent $\operatorname{BESS}(n)$. Current-voltage characteristics are shown in (7) and (8) for charging and discharging conditions, respectively. This is a modified version of the Shepherd model, which takes into account changes of open-circuit voltage with the SOC, ohmic losses related to grid resistance, active mass resistance, the resistance of the electrolyte, and the battery overvoltage.

$$
\begin{gathered}
V_{t}^{n}=V_{o}-\left(V_{D}\right) D O D_{t}^{n}+R_{C}\left(\frac{I_{t}^{n}}{C_{10}^{n}}\right)+ \\
R_{C} M_{C}\left(\frac{I_{t}^{n}}{C_{10}^{n}}\right)\left(\frac{S O C_{t}^{n}}{C_{C}-S O C_{t}^{n}}\right) \\
\ngtr I_{t}^{n}>0 \ngtr t=1, \ldots, T ; \\
V_{t}^{n}=V_{o}-\left(V_{D}\right) D O D_{t}^{n}+R_{D}\left(\frac{I_{t}^{n}}{C_{10}^{n}}\right)+ \\
R_{D} M_{D}\left(\frac{I_{t}^{n}}{C_{10}^{n}}\right)\left(\frac{D O D_{t}^{n}}{C_{D}-D O D_{t}^{n}}\right) \\
\ngtr I_{t}^{n} \leq 0 \ngtr t=1, \ldots, T .
\end{gathered}
$$

The relationship between the gassing current and the SOC during charging conditions is shown in (9) and (10), developed from the Butler-Volmer characteristic. In (9), the reader can note how the model considers only those current values whose associated energy is effectively stored on the LAB by subtracting the current related to the gassing process $\left(I_{G, t}^{n}\right)$ from the external charging current $\left(I_{t}^{n}\right)$. 


$$
\begin{gathered}
S_{O} C_{t}^{n}=S O C_{t-1}^{n}+\int_{0}^{t} \frac{I_{\tau}^{n}-I_{G, \tau}^{n}}{C_{10}^{n}} d \tau \forall t=1, \ldots, T ; \quad(9) \\
I_{G, t}^{n}=\left(\bar{C}_{10}^{n}\right)\left(\bar{I}_{G}\right) \exp \left(C_{U}\left[V_{t}^{n}-\bar{V}_{G}\right]+C_{T}\left[T_{A, t}^{n}-\bar{T}_{G}\right]\right) \\
\forall t=1, \ldots, T .
\end{gathered}
$$

Otherwise, in (10), the reader can note how the gassing current increases exponentially with the cell voltage and temperature, which justify the exponential reduction of the coulombic efficiency at high SOC values. During discharging conditions, the SOC could be estimated by applying (9), neglecting the effects of the gassing phenomena expressed in (10) [31]. In addition, it is important to consider each SOC value between its minimum value and $1 \quad\left(S_{0} C_{t}^{n} \in\right.$ $\left.\left[S_{O} O C_{\min }^{n}, 1\right] ; n=1, \ldots, N ; t=1, \ldots, T\right)$; the charge controller technically carries this out to protect the battery cell against over-discharging conditions. To guarantee the safe operation of the BESS, the charging $\left(I_{t}^{n}>0\right)$ and discharging $\left(I_{t}^{n}<0\right)$ currents are limited to determined values suggested by the battery manufacturer; this idea is presented in the constraint (11),

$$
-I_{M}^{n} \leq I_{t}^{n} \leq I_{M}^{n} \ngtr t=1, \ldots, T .
$$

During charging conditions, the battery current is defined in the interval $\left(0, I_{M}^{n}\right]$, so that the current value at which the battery voltage is close to its corresponding regulation value $\left(V_{R}\right)$ (which is established to protect the battery cell against over-charging conditions) is obtained from the application of the bisection method (BM) [32], according to Algorithm I.

During discharging conditions, the battery current is defined in the interval $\left[-I_{M}^{n}, 0\right)$ so that it can be estimated from the energy stored in the battery, which is available to be discharged in a single time step $(\Delta t)$; this is expressed in (12):

$$
I_{t}^{n}=-\min \left\{\frac{\left(S O C_{t}^{n}-S O C_{\min }^{n}\right) C_{10}^{n}}{\Delta t}, I_{M}^{n}\right\}
$$

Finally, those situations with no power transaction between the LAB and SG are simulated by assigning $I_{t}^{n}=0$. Figs. 2 and 3 illustrate the results obtained from the simulation of a battery cell of $300 \mathrm{Ah}\left(C_{10}^{1}=300 \mathrm{Ah}\right)$ when the battery current is limited to $10 \mathrm{~A}\left(I_{M}^{1}=10 \mathrm{~A}\right)$ and $30 \mathrm{~A}\left(I_{M}^{1}=30 \mathrm{~A}\right)$, respectively.

It is possible to observe how the charging current is exponentially reduced to maintain the battery voltage at the corresponding regulation value, which directly influences the power taken from the grid. In addition, the reader can observe how the maximum power to be taken from the grid can be reduced by using only the variable $I_{M}^{n}$, according to Fig. 3, from $60 \mathrm{~W}$ to $20 \mathrm{~W}$; this fact is used to limit the amount of power to be taken by or injected into the SG to preserve its safe operation. Once a battery cell has been analyzed, all variables are scaled to consider the total capacity of the battery bank as presented in (13):

$$
P_{B, t}^{n}=\left(V_{t}^{n} I_{t}^{n}\right) N_{s}^{n} N_{p}^{n}
$$

ALGORITHM I

ESTIMATION OF BATTERY CHARGING CURRENT Step 1: Set an estimation error of $B M\left(\Delta V_{R}\right)$.

Step 2: Set the maximum number of iterations $(K)$ at a value higher than $\log \left(I_{M}^{n} / \Delta V_{R}\right) / \log (2)$.

Step 3: Set $I_{L F} \leftarrow 0$ and $I_{R H} \leftarrow I_{M}^{n}$.

Step 4: Set $k \leftarrow 1$.

Step 4.1: Set $I_{A} \leftarrow I_{L F}$; calculate $V_{L F}$ from the evaluation of $I_{A}$ on (7), (9), and (10); and the corresponding error is estimated as $\Delta V_{L F}=V_{R}-V_{L F}$.

Step 4.2: Set $I_{B} \leftarrow\left(I_{L F}+I_{R H}\right) / 2$; calculate $V_{R H}$ from the evaluation of $I_{B}$ on (7), (9), and (10); and the corresponding error is calculated as $\Delta V_{R H}=V_{R}-V_{R H}$.

Step 4.3: If $\left\{\left(\Delta V_{L F}\right)\left(\Delta V_{R H}\right)>0\right\}$, then $I_{L F} \leftarrow I_{B}$, else $I_{R H} \leftarrow I_{B}$.

Step 5: If $\{k<K\}$, then $k \leftarrow k+1$; go to Step 4.1 or stop

Then, the variable efficiency of the bidirectional converter is incorporated using (14) and (15).

$$
\begin{gathered}
\eta_{C}^{n}=\frac{P_{B, t}^{n}}{R_{A}\left(P_{C}^{n}\right)+\left(1+M_{A}\right) P_{B, t}^{n}} ; \\
P_{E, t}^{n}= \pm \frac{\left|P_{B, t}^{n}\right|-R_{A}\left(P_{C}^{n}\right)}{\left(1+M_{A}\right)} .
\end{gathered}
$$

Power from/to LAB $\left(P_{E, t}^{n}\right)$ is estimated by (15) only when the power from/to $\operatorname{LAB}\left(P_{B, t}^{n}\right)$ is higher than factor $\left(R_{A} P_{C}^{n}\right)$ and when $P_{B, t}^{n}$ is lower than the rated power of the bidirectional converter $\left(P_{C}^{n}\right)$. In other cases, $P_{E, t}^{n}$ is assumed to be zero. Corresponding parameters for modeling efficiency variations have been obtained using information taken from [33].

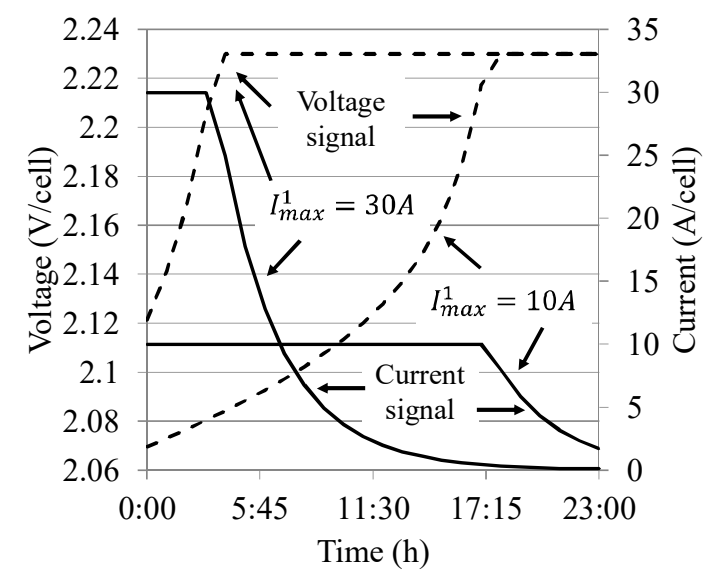

Fig. 2. Controlled voltage and current of a typical battery cell. 


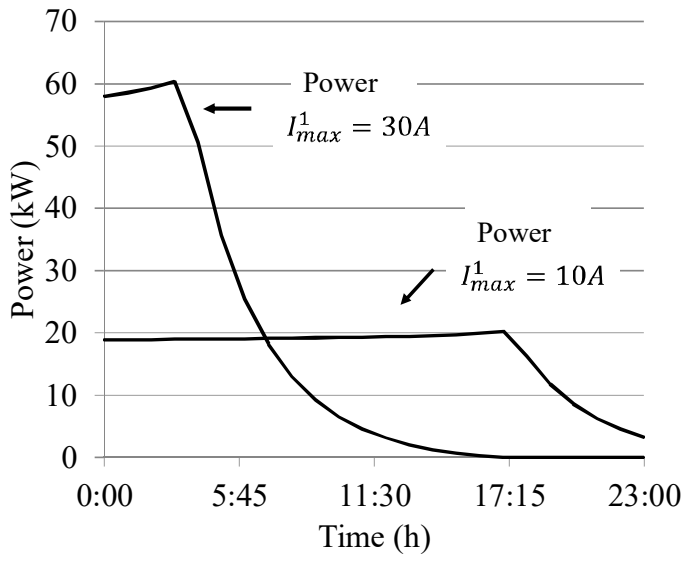

Fig. 3. Controlled power of a typical battery cell.

\section{Optimization of Day-Ahead Operation}

As stated before, an integer-coded GA has been used in this paper to determine the optimal operation of a LAB enrolled in an RT pricing program on a daily basis. In the implementation used in this work, each individual is represented by an integer vector with $T=24$ elements, such as this: $\vec{b}_{i}=\left(\begin{array}{llll}b_{1}^{i} & b_{2}^{i} & \cdots & b_{t}^{i}\end{array} \cdots\right.$ $b_{T}^{i}$ ) with $i=1, \ldots, I$.

Each element $\left(b_{t}^{i}\right)$ corresponds to the operative condition of the LAB; if $b_{t}^{i}=1$, the charging of the LAB is carried out; otherwise, if $b_{t}^{i}=-1$, the discharging of the LAB is done; and finally, if $b_{t}^{i}=0$, there is no power transaction between the BESS and SG; it is the equivalent of disconnecting the BESS from the $\mathrm{SG}$; in this way, the population of the GA is presented in (16) and (17):

$$
\begin{gathered}
B=\left[\begin{array}{c}
\vec{b}_{1} \\
\vdots \\
\vec{b}_{i} \\
\vdots \\
\vec{b}_{I}
\end{array}\right] ; \\
\vec{b}_{i}=\left[\begin{array}{lllll}
b_{1}^{i} & \ldots & b_{t}^{i} & \ldots & b_{T}^{i}
\end{array}\right] \bowtie i=1, \ldots, I .
\end{gathered}
$$

In Fig. 4 , it is shown how a determined individual $\left(\vec{b}_{i}\right)$ is included in the population $(B)$, which is expressed as a matrix. The optimization algorithm aims to minimize the Daily Net Cost (DNC). For a determined individual $\left(\vec{b}_{i}\right)$ in the population, DNC is estimated according to (18):

$$
D_{G, i}^{n}=\sum_{t=1}^{T}\left(E_{t}\right)\left(P_{G, t}^{n, i}\right) \ngtr i=1, \ldots, I .
$$

The variable $P_{G, t}^{n, i}$ is related to vector $\vec{b}_{i}$ through the simulation process of III-B. In other words, the values of $P_{G, t}^{n, i}$ are obtained from the simulation process of (7)-(12) and Algorithm I, and they are equal to the power from/to LAB $\left(P_{G, t}^{n, i}=P_{E, t}^{n} \ngtr t=1, \ldots, T\right)$.

This means these factors are not represented in our dailybased optimization model. Once the population size $(I)$, the number of generations $(G)$, the crossover rate $(X)$, and the mutation rate $(M)$ have been defined, the algorithm could be implemented by following the steps of Algorithm II.

In this work, the number of possible combinations of individuals is $3^{24}=2.82 \cdot 10^{11}$. Evaluating all of them would take years of computing, which is obviously inadmissible. Therefore, it is impossible to know if the best solution found by the GA is really the true optimal solution. However, we can be confident that the optimal solution, or a near-optimal solution, will be found.

The three steps described in Algorithm I are sequentially repeated until the maximum number of generations $(I)$ is reached; after the analysis of all of the generations, the individual with the highest fitness value is chosen as the solution to define the near-optimal schedule of $\operatorname{BESS} n\left(\bar{P}_{G, t}^{n}\right)$. The fitness function of (19) establishes a linear relationship among all individuals due to the fact that it is defined by the position of the individual in the sorted list instead of the value of the objective function (DNC), which could have important differences between them.

The simulation process and evaluation of a determined individual $\left(\vec{b}_{i}\right)$ could be understood easily by analyzing Fig. 4 . As can be observed, at $t=1 \mathrm{~h}, \vec{b}_{i}=-1$ and the LAB should be discharged so that the battery voltage is estimated by using (8), the SOC is estimated by using (9) with $I_{G, t}^{n} \rightarrow 0$, and the discharging current is estimated according to (12). Now, at time $t, \vec{b}_{i}=1$ and the LAB should be charged; hence, the battery voltage is estimated by using (7), the SOC is estimated by using (9) and (10), and the charging current is estimated by using Algorithm I. Finally, at $t=T, \vec{b}_{i}=0$, and there is no power transaction between the BESS and SG. Then, the battery voltage is estimated through (8), and $S O C_{t}^{n}=S O C_{t-1}^{n}$. Once the BESS power has been calculated from the simulation process previously described, the DNC could be estimated easily for the individual under analysis by means of (18).
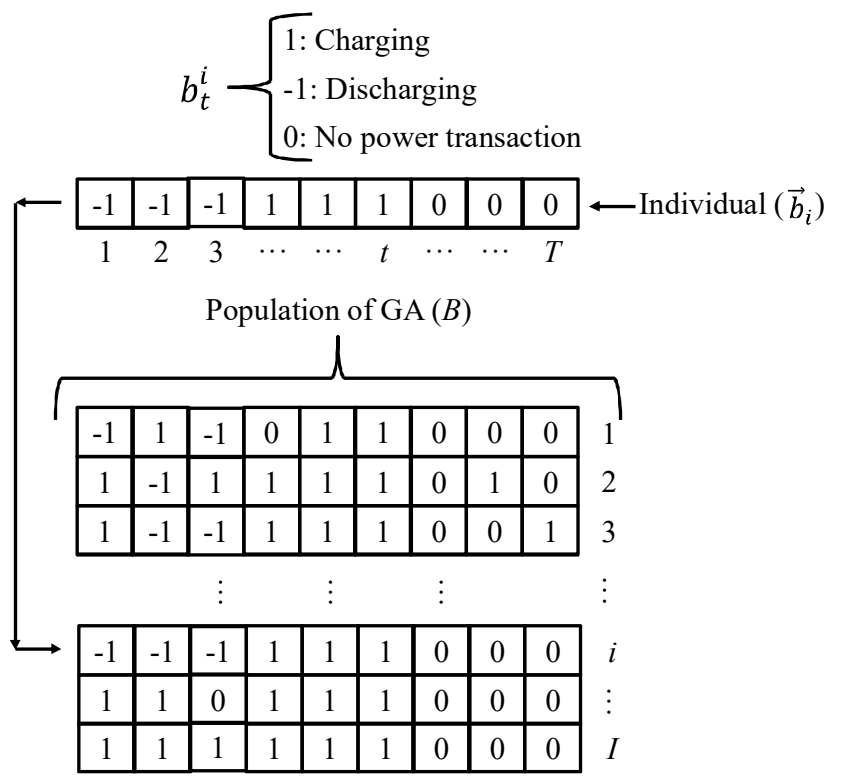

Fig. 4. A typical individual in the GA population. 
ALGORITHM II

IMPLEMENTATION OF GA FOR BESS SCHEDULING

Step 1: The initial population is randomly generated by considering only $-1,0$, and 1 . To improve the algorithm's efficiency, an additional individual is created and inserted into the population (B in Fig. 4 and (16)). This individual is designed by taking into account the hourly profile of the FEP; if the price at determined hour $t$ is lower than the daily average, the charging operation is suggested by assigning 1 to the element of this individual $\left(b_{t}^{i}=1\right)$; otherwise, if the price is higher than the daily average, -1 is assigned $\left(b_{t}^{i}=-1\right)$; finally, if the price is equal to the daily average, no control action is considered, by assigning 0 to the corresponding element $\left(b_{t}^{i}=0\right)$. Besides of those individuals randomly generated this additional individual is added improving the general performance of the algorithm.

Step 2: The DNC is evaluated for each individual in the population using (18), which depends on the FEP and the scheduled power of the $L A B$ at each time step. Once the $D N C$ of each individual has been calculated, all of them are sorted in a list according to their DNCs $\left(D_{G, i}^{n} \downarrow i=1, \ldots, I\right)$, from the smallest to the largest value; finally, according to this order, the fitness of each individual is assigned by using (19):

$$
f_{i}^{n}=\frac{(I+1)-i}{\sum_{i}(I+1-i)} \ngtr i=1,2, \ldots, I
$$

Step 3: Reproduction, crossing, and mutation operators are applied; hence, the population of the next generation is defined. Frequently, high values of the crossover rate are used $(X \rightarrow 1)$, while very low values of the mutation rate are typically used $(M \rightarrow 0)$.

Regarding the BESS aggregator, Fig. 5 presents its general structure. As can be observed, the aggregator is composed of several BESSs similar to that previously shown in Fig. 1, which operates in a decentralized way; the BMS of each BESS $n$ optimizes its own operation using an FEP provided by the aggregator, which is responsible for guaranteeing that the total power from or to the aggregated $\operatorname{BESS}\left(P_{A, t}\right)$ is within the corresponding limit defined by the Distribution Network Operator (DNO); it is then designated as $\left(S_{L}\right)$.

In this way, the optimal scheduling of each BESS is added as presented in (20); then, the excess power required or supplied by the BESS aggregator $\left(\Delta S_{L}\right)$ is estimated according to (21), where the limit imposed by the SG is included.

$$
\begin{gathered}
\sum_{n=1}^{N} \bar{P}_{G, t}^{n}=P_{A, t} \ngtr t=1, \ldots, T ; \\
\Delta S_{L}=\max \left\{\left|P_{A, t}\right| \ngtr t=1, \ldots, T\right\}-S_{L} ;
\end{gathered}
$$

To remove this excess in the power transaction, two mechanisms have been evaluated: Power Reduction by Capacity (PRC) and Uniform Power Reduction (UPR).
In the PRC strategy, it is assumed that the reduction of the BESS-aggregator power is carried out according to the capacity of each BESS; in other words, if a reduction in the power transaction between the BESS aggregator and SG is required, those BESSs with higher capacities reduce their power to be charged or discharged at higher magnitudes than the other BESSs of lower capacities.

This idea is mathematically expressed in (22), where the weighting factor $\left(W_{n} \bowtie n=1, \ldots, N\right)$ reflects the reduction degree of each BESS. The power reduction of each BESS $n$ is effectively applied by setting the maximum current $\left(I_{M}^{n}\right)$ to a convenient value.

$$
W_{n}=C_{10}^{n} N_{s}^{n} N_{p}^{n} /\left(\sum_{n=1}^{N} C_{10}^{n} N_{s}^{n} N_{p}^{n}\right) \rtimes n=1,2, \ldots, N .
$$

With respect to the UPR strategy, it is assumed that the reduction of the BESS-aggregator power is uniformly carried out by all BESSs integrated in the aggregator; in this way, the power reduction and consequently its effects are equally distributed over the enrolled BESSs.

This idea is implemented by assigning the value of each weighting factor $\left(W_{n} \ngtr n=1, \ldots, N\right)$ according to (23):

$$
W_{n}=1 / N \bowtie n=1,2, \ldots, N .
$$

Once the actual condition of the BESS aggregator has been defined through variable $\left(\Delta S_{L}\right)$, excess operating power is eliminated by applying Algorithm III combined with (22) or (23) depending on the strategy to be used (PRC or UPR, respectively). Both approaches take advantage of the communication infrastructure of the SG to accommodate the BESS aggregator power with regard to the technical capabilities of the distribution system.

As in Algorithm III (specifically in (24) and (26)), the maximum charging power is required. It is calculated by using the regulation voltage (with a typical value equal to 2.23 $\mathrm{V} /$ cell) because this is the maximum operational voltage at which the charge controller would operate the LAB bank; that is the reason $V_{R}=2.23 \mathrm{~V} /$ cell is included in these equations.

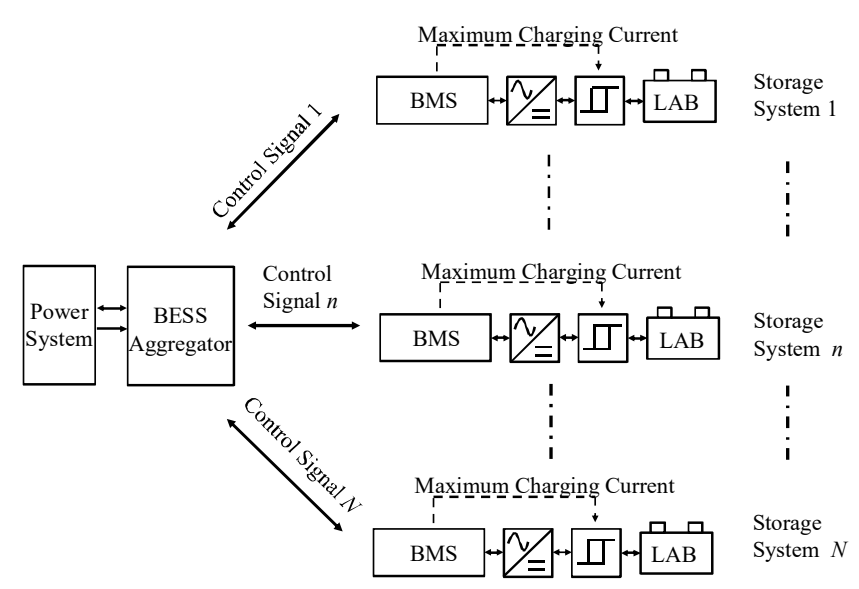

Fig. 5. General architecture of a BESS aggregator. 
ALGORITHM III

REDUCTION ON POWER SCHEDULING OF BESS AGGREGATOR Step 1: If $\left\{\Delta S_{L}>0\right\}$, go to step 2, or, otherwise, stop.

Step 2: Calculate the maximum charging power allowed for each BESS; this is estimated by using (24):

$$
P_{M}^{n}=\left(I_{M}^{n} V_{R}\right) N_{s}^{n} N_{p}^{n} \ngtr n=1,2, \ldots, N .
$$

Step 3: Estimate the reduction in the maximum charging or discharging power allowed for each BESS by means of (25):

$$
P_{r}^{n}=\left(1-W_{n}\right) P_{M}^{n} \ngtr n=1,2, \ldots, N .(25
$$

Step 4: Calculate the new limit of the maximum charging or discharging current of each BESS using (26):

$$
I_{M}^{n}=P_{r}^{n} /\left(V_{R} N_{s}^{n} N_{p}^{n}\right) \rtimes n=1,2, \ldots, N .
$$

Step 5: Using the value of $I_{M}^{n}$ previously assigned in Step 4, evaluate the performance of each BESS and the power transaction between the BESS aggregator and $S G\left(P_{A, t} \downarrow t=\right.$ $1, \ldots, T)$; estimate $\Delta S_{L}$ according to (21); and go to Step 1 .

\section{CASE STUdy}

The comprehensive methodology developed in this work for the optimal management of the BESS is illustrated in this section by analyzing the independent and aggregated operation using data of the Spanish electricity market of the years 20132016 [35]. This is done to evaluate the influence of forecasting error and power-system limitations over a representative time period. Sub-section IV-A describes the results obtained from the FEP process, and IV-B and IV-C evaluate the capabilities of the proposed method for controlling an independent BESS and a BESS aggregator. Finally, in IV-D, the impact of forecasting error and the SG capacity are statistically analyzed. All numerical experiments have been implemented in MATLAB ${ }^{\circledR}$ in a computer with $\mathrm{i7-3630QM} \mathrm{CPU}$ at 2.40 $\mathrm{GHz}, 8 \mathrm{~GB}$ of RAM, and a 64-bit operating system.

\section{A. Electricity Price Forecasting using Spanish Market Data}

The FEP was performed by applying the process described in III-A based on time-series analysis. Two HWEP databases were used; the first database corresponds to the time period of January 1 to February 7, 2016, measured on an hourly basis. This time series was used to carry out the corresponding FEP for February 8, 2016, using the discrete functions of $F_{H}$ and $F_{G}$ with 150 intervals. Thus, the resulting information served as an input to the optimization analysis under independent and aggregated modes for this day. The second database corresponds to the time period of December 1, 2013, to December 31, 2015; this database was used to analyze the influence of forecasting error and the SG capacity on the performance of BESS operation from a statistical perspective.

Regarding the ARMA model, a maximum of 30 coefficients was considered for autoregressive and movingaverage parameters, selecting the maximum number of parameters between those suggested by the BIC and AIC criteria. As described earlier, the first database was used to perform time-series analysis for February 8, 2016; thus, the ARMA coefficients selected $(P=5$ and $Q=2)$ are shown in Tables I and II. With respect to statistical checking, $\chi^{2}(\alpha=0.05)=106.394$ and $S=34.036$ with 84 degrees of freedom $(L-P-Q=84)$ were calculated. Fig. 6 shows the obtained FEP presenting the actual and forecasted profiles.

Respecting the analysis of the second HWEP database, a time series of December 2013 was used for the prediction of January 2014; more precisely, the data of December 2013 were analyzed to estimate the order of the corresponding ARMA model; then, price forecasting over each day of January was carried out, updating the values of the ARMA model coefficients. This process was sequentially repeated over the years of 2014 and 2015, so the error related to the FEP was statistically investigated.

The results related to the ARMA model's coefficients of the second HWEP database are shown in Table III, while a histogram of forecasting error is presented in Fig. 7, where the mean and standard deviation are estimated as $0.9711 € / \mathrm{MWh}$ and $9.5224 € / \mathrm{MWh}$, respectively. The incorporation of these data in optimal BESS operation is carefully described in subsections IV-B, IV-C, and IV-D.

\section{B. Operation of an Independent BESS}

This sub-section illustrates the operation of an independent BESS with the structure shown in Fig. $1(N=1)$ conformed by $2 \mathrm{~V}$-cells of $C_{10}^{1}=1000 \mathrm{Ah}$ with $S O C_{\text {min }}^{1}=0.3$, an initial SOC equal to $0.3\left(S O C_{0}^{1}=0.3\right), 200$ serial-connected cells $\left(N_{s}^{1}=200\right)$, and one string $\left(N_{p}^{1}=1\right)$. The maximum charging or discharging current per cell was adjusted to $100 \mathrm{~A} /$ cell $\left(I_{M}^{1}=I_{10}^{1}\right)$. The actual electricity price and the FEP of February 8, 2016, as previously described, were jointly used with an integer-coded GA with 200 individuals $(I=200), 100$ generations $(G=100)$, a crossover rate equal to $90 \%(X=90 \%)$, and a mutation rate of $1 \%(M=1 \%)$. The ambient temperature was assumed to be constant, equal to $298 \mathrm{~K}\left(T_{A, t}^{n}=298 \mathrm{~K} \forall t=1, \ldots, 24\right)$, which means its effects on the LAB are not considered.

TABLE I

AUTOREGRESSIVE PARAMETERS

\begin{tabular}{lllll}
\multicolumn{5}{c}{ AUTOREGRESSIVE PARAMETERS } \\
\hline$\phi_{1}$ & $\phi_{3}$ & $\phi_{4}$ & $\phi_{5}$ \\
\hline 2.7199 & -2.7750 & 1.1257 & -0.0962 & 0.0155 \\
\hline \multicolumn{5}{c}{ TABLE II } \\
& MOVING AVERAGE PARAMETERS \\
\hline$\theta_{1}$ & $\theta_{2}$ \\
\hline-1.6858 & 0.9397 \\
\hline
\end{tabular}

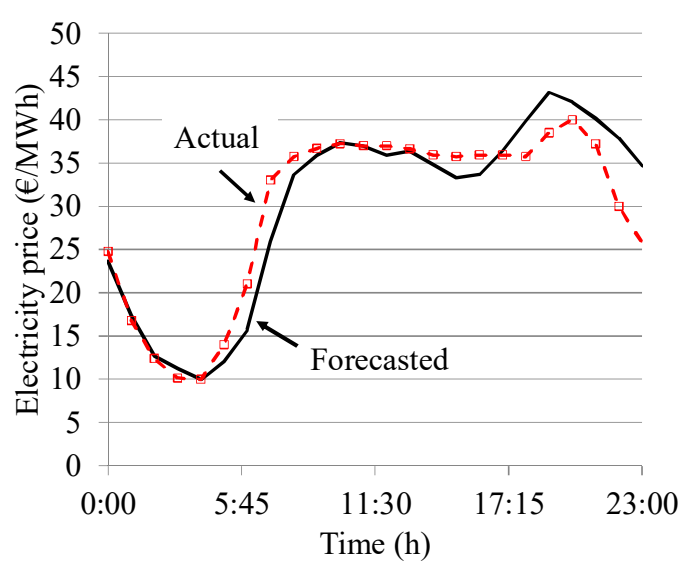

Fig. 6. Actual and predicted electricity prices (2/8/2016). 
TABLE III

ARMA MODELS FOR PRICE FORECASTING DURING 2014 AND 2015.

\begin{tabular}{ccccccc}
\hline Year & Month & $P$ & $Q$ & $L-P-Q$ & $S$ & $\chi^{2}(\alpha=0.05)$ \\
\hline 2013 & Dec & 10 & 9 & 204 & 218.592 & 238.322 \\
& Jan & 15 & 3 & 205 & 220.3015 & 239.4034 \\
& Feb & 5 & 9 & 188 & 189.1803 & 220.9908 \\
& Mar & 14 & 4 & 205 & 200.9628 & 239.4034 \\
& Apr & 18 & 20 & 178 & 201.69 & 210.1298 \\
& May & 18 & 14 & 191 & 216.7428 & 224.2446 \\
2014 & June & 9 & 20 & 187 & 177.649 & 219.9058 \\
& July & 14 & 12 & 197 & 230.7463 & 243.5138 \\
& Aug & 9 & 15 & 199 & 216.2852 & 232.9118 \\
& Sept & 7 & 8 & 201 & 256.5014 & 235.0765 \\
& Oct & 10 & 6 & 207 & 248.3143 & 241.5657 \\
& Nov & 3 & 6 & 207 & 198.8872 & 241.5657 \\
& Dec & 3 & 16 & 204 & 206.8395 & 238.322 \\
& Jan & 12 & 2 & 209 & 248.929 & 243.7272 \\
& Feb & 6 & 2 & 194 & 252.4932 & 227.4964 \\
& Mar & 18 & 4 & 201 & 202.6716 & 235.0765 \\
& Apr & 6 & 4 & 206 & 178.048 & 240.4847 \\
& May & 17 & 13 & 193 & 198.7169 & 226.4127 \\
2015 & June & 7 & 6 & 203 & 233.7341 & 237.2404 \\
& July & 6 & 16 & 201 & 251.1403 & 235.0765 \\
& Aug & 17 & 9 & 197 & 188.617 & 230.7463 \\
& Sept & 17 & 4 & 195 & 130.6394 & 228.5799 \\
& Oct & 5 & 4 & 214 & 249.264 & 249.1275 \\
& Nov & 10 & 20 & 186 & 170.1237 & 218.8205 \\
\hline
\end{tabular}

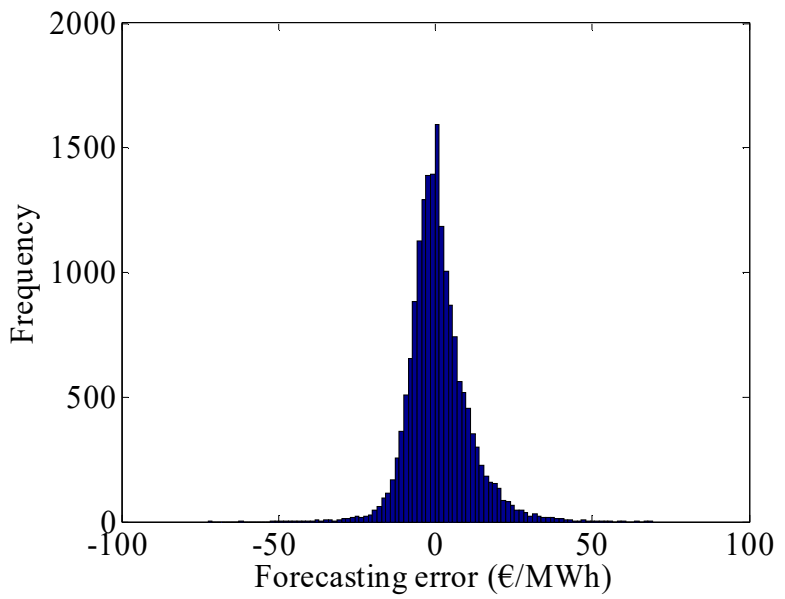

Fig. 7. Histogram of electricity-price forecasting error.

Fig. 8 shows the convergence of the GA completed in 49.127 seconds. Otherwise, the behavior of the LAB during charging conditions was estimated by the $\mathrm{BM}$ considering $\Delta V_{R}=10^{-10}$.

As can be observed, the objective function (DNC) takes negative values due to the fact that BESS discharging (selling energy to SG) has been modeled with a negative sign (sign of the $\mathrm{LAB}$ discharging current and power); during the hourly operation, the amount of energy expected to be sold is higher than the amount expected to be bought from the SG.

The optimal LAB operation in terms of power transaction, battery voltage, and SOC is shown in Figs. 9 and 10, where, initially, BESS is charged during low-price periods in the early morning, is modestly discharged during late-morning hours, has a resting period during midday hours, is modestly charged during the afternoon, has a another resting period after this, and is heavily discharged at high-price periods during the night hours, following the trend of the FEP.

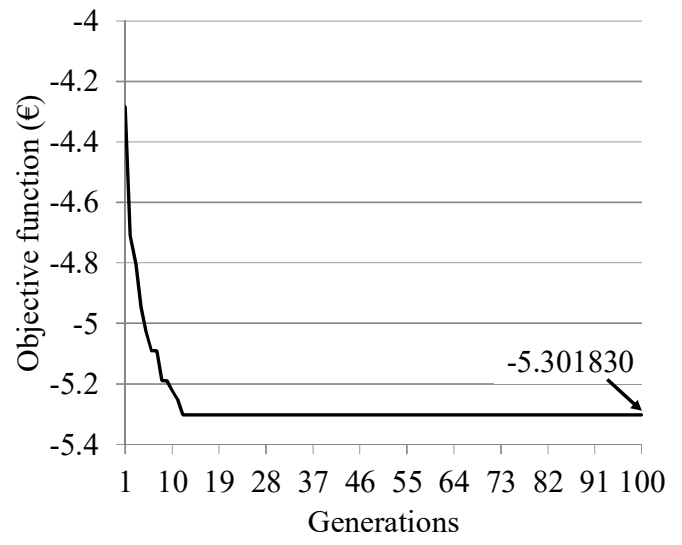

Fig. 8. Convergence of GA (2/8/2016).

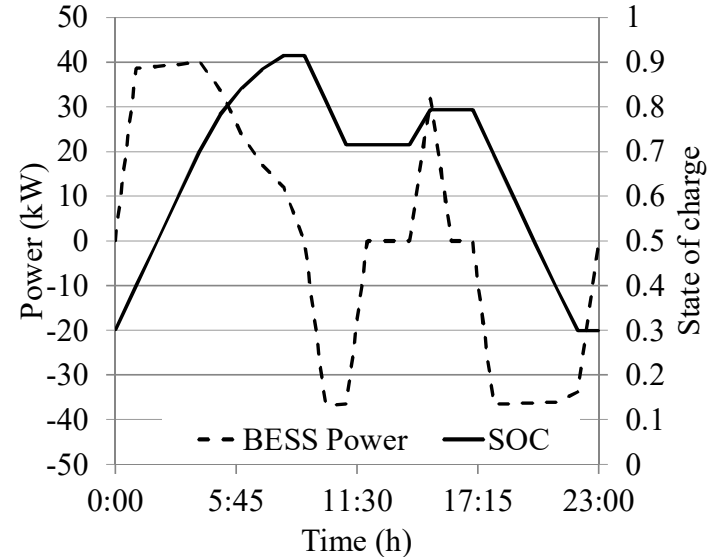

Fig. 9. Optimal scheduling of BESS (2/8/2016).

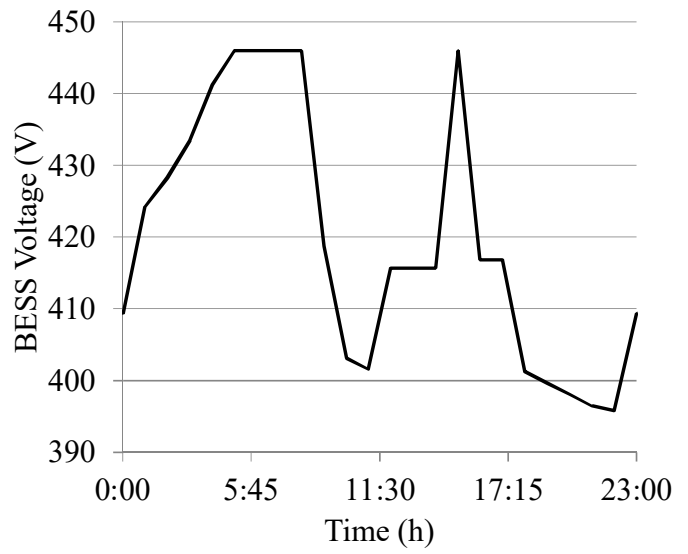

Fig. 10. Voltage of BESS (2/8/2016).

As the limit of the distribution system is not being taken into account in this section (unconstrained operation), a nonstrategy for BESS power reduction is applied. The forecasted DNC is estimated as $-5.301830 €$ (obtained from the implementation of the proposed GA shown in Fig. 8), while the actual DNC is $-4.192483 €$ (obtained from the application of the management strategy suggested by the GA over the actual price signal, i.e., evaluating (18) using the actual prices instead of the forecasted ones). This result shows a reduction in the expected revenue from the power transaction between the LAB and SG of $€ 1.109$, which is around $21 \%$ and is directly related to the forecasting error of electricity prices. 


\section{Operation of a BESS Aggregator}

In this sub-section, a BESS aggregator with 15 systems, and with the architecture presented in Fig. $5(N=15)$, is analyzed by considering the price forecasting calculated in IV-A (the FEP of Fig. 6) and the optimization parameters used in IV-B. The data for each system are presented in Table IV with $S O C_{\text {min }}^{n}=0.3 \ngtr n=1, \ldots, 15$, while the maximum capacity of the SG imposed by the DNO is considered to be $1000 \mathrm{~kW}$ $\left(S_{L}=1000\right)$.

TABLE IV

CHARACTERISTICS OF BESSS INTEGRATED TO THE AGGREGATOR

\begin{tabular}{cccccc}
\hline$n$ & $C_{10}^{n}$ & $N_{S}^{n}$ & $N_{p}^{n}$ & $P_{C}^{n}$ & BESS $(\mathrm{kWh})$ \\
\hline 1 & 1000 & 150 & 15 & 502 & 4500 \\
2 & 300 & 50 & 10 & 34 & 300 \\
3 & 500 & 15 & 5 & 9 & 75 \\
4 & 250 & 75 & 15 & 63 & 562.5 \\
5 & 1500 & 100 & 20 & 669 & 6000 \\
6 & 550 & 30 & 25 & 92 & 825 \\
7 & 230 & 60 & 50 & 154 & 1380 \\
8 & 110 & 55 & 18 & 25 & 217.8 \\
9 & 750 & 15 & 5 & 13 & 112.5 \\
10 & 300 & 10 & 16 & 11 & 96 \\
11 & 270 & 100 & 14 & 85 & 756 \\
12 & 450 & 5 & 10 & 6 & 45 \\
13 & 140 & 15 & 40 & 19 & 168 \\
14 & 550 & 35 & 35 & 151 & 1347.5 \\
15 & 850 & 10 & 35 & 67 & 595 \\
\hline
\end{tabular}

Using this information, the strategies of PRC and UPR are analyzed and discussed.

Regarding the PRC strategy, from the application of the proposed algorithm described in III-C (Algorithm III with $W_{n} \ngtr n=1, \ldots, N$ defined according to (22)), the scheduling shown in Fig. 11 was reached; it is possible to observe how the proposed methodology produces a feasible schedule from the perspective of the DNO. To obtain these results, an iterative process of reduction in the maximum battery current $\left(I_{M}^{n} \ngtr n=1, \ldots, 15\right)$ was carried out as presented in Fig. 12 and Table VI (second column). The entire procedure took only three iterations; on the one hand, the proposed methodology is computationally efficient due to the fact that those BESSs with high contributions to the SG overload experience a higher reduction in their maximum power transaction, which speeds up the convergence of the approach; on the other hand, it is computationally fast because the GA is computed on the BMS of each BESS in a decentralized manner.

Initially, a 10h-current per cell was assumed to be a maximum limit $\left(I_{M}^{n}=I_{10}^{n}=C_{10}^{n} / 10\right)$; the overload of the SG is shown in Table VI in the first row and second column; to remove this unacceptable condition, $I_{M}^{n}$ was sequentially reduced until the values shown in Table VIII (the second column) and the white bars of Fig. 12 where reached.

Table $\mathrm{V}$ presents the estimation of the revenue and a comparison between the constrained and unconstrained conditions, observing a considerable reduction in the economic benefit due to SG limitations and forecasting error. As the calculation process is carried out in a decentralized way, the computational time per iteration is similar to that obtained during the independent BESS operation (reported in IV-B).

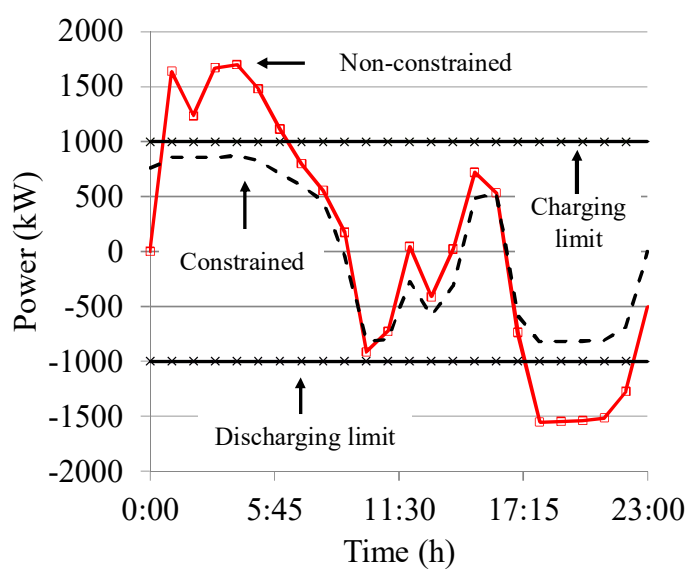

Fig. 11. Optimal operation of BESS aggregator (2/8/2016) (PRC).

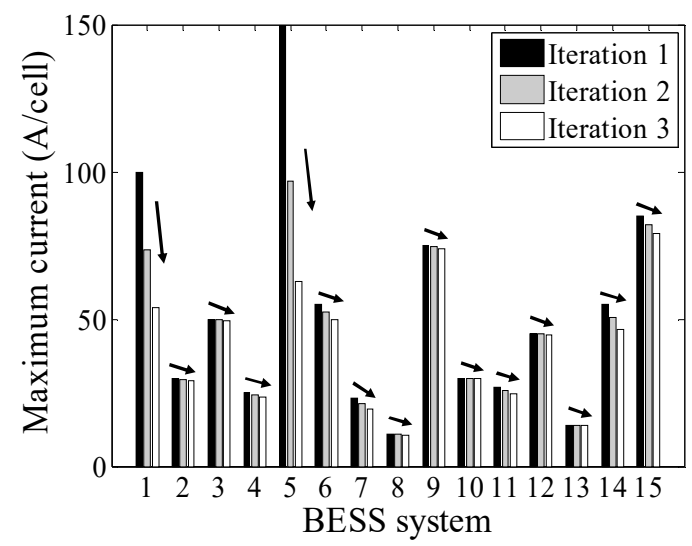

Fig. 12. Maximum current per cell for each BESS (2/8/2016) (PRC).

TABLE V

ECONOMIC PERFORMANCE OF BESS AGGREGATOR (PRC STRATEGY)

\begin{tabular}{ccc}
\hline Solution & \multicolumn{2}{c}{ Daily Net Cost $(€)$} \\
\cline { 2 - 3 } & Forecasted & Actual \\
\hline Constrained & -138.124144 & -109.811260 \\
Unconstrained & -217.344787 & -165.666463 \\
\hline
\end{tabular}

With respect to the UPR strategy, from the application of the proposed algorithm described in III-C (Algorithm III with $W_{n} \downarrow n=1, \ldots, N$ defined according to (23)), the scheduling shown in Fig. 13 was reached; it is possible to observe how the proposed methodology produces a feasible schedule from the perspective of the DNO. To obtain these results, an iterative process of reduction in the maximum battery current $\left(I_{M}^{n} \ngtr n=1, \ldots, 15\right)$ was carried out as presented in Fig. 14 and Table VIII. The entire procedure took only eight iterations.

As previously explained, a 10h-current per cell was assumed to be a maximum limit; the overload of the SG is shown in Table VI in the first row and third column. To remove this unacceptable condition, $I_{M}^{n}$ was sequentially reduced until the values shown in Table VIII (the third column) and the gray bars of Fig. 14 where reached.

Table VII presents the estimation of the revenue and a comparison between the constrained and unconstrained conditions, observing a considerable reduction in the economic benefit due to SG limitations and forecasting error. 
The PRC and UPR strategies could be compared by analyzing the obtained results; from the comparison between the results presented in tables V and VII, an improvement of $8.3 \%$ of the UPR over the PRC using the FEP and $7.4 \%$ using actual prices could be observed. This fact can be observed qualitatively in figs. 11 and 13, where the amount of power charged and discharged to the SG have important differences, being higher when the UPR strategy is applied.

However, another relevant result arises when Figs. 12 and 14 are compared, and Table VI is analyzed because the PRC strategy has higher computational efficiency, as it is able to remove the overload of the SG more quickly (in fewer iterations) than the UPR strategy. This characteristic could be particularly useful for managing charging or discharging power during emergency conditions or when the operating conditions of the SG are under risk.

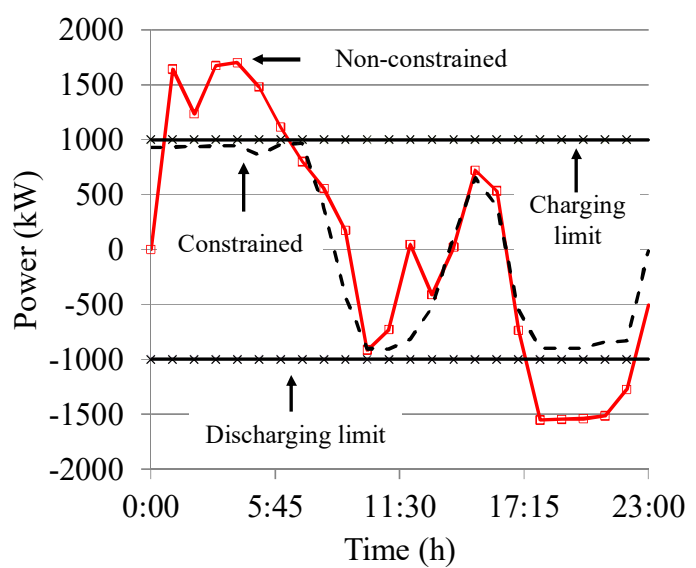

Fig. 13. Optimal operation of BESS aggregator (2/8/2016) (UPR).

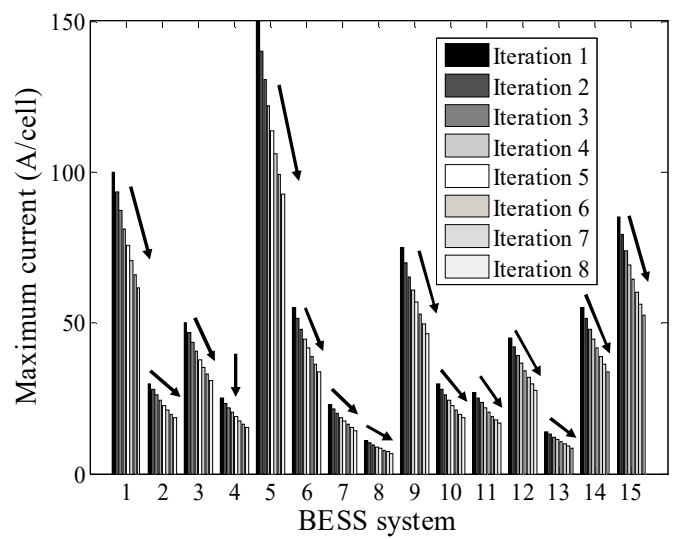

Fig. 14. Maximum current per cell for each BESS (2/8/2016) (UPR).

TABLE VI

CONVERGENCE OF THE PROPOSED METHODOLOGY

\begin{tabular}{ccc}
\hline$k$ & $\Delta S_{L}(\mathrm{PRC})$ & $\Delta S_{L}(\mathrm{UPR})$ \\
\hline 1 & 700.981549652121 & 700.9815 \\
2 & 322.248988901942 & 579.4792 \\
3 & 58.0583356121276 & 488.557 \\
4 & ------- & 403.5581 \\
5 & ------ & 290.3378 \\
6 & ------- & 208.3285 \\
7 & ------ & 122.3642 \\
8 & ------ & 50.25158 \\
\hline
\end{tabular}

TABLE VII

ECONOMIC PERFORMANCE OF BESS AGGREGATOR(UPR STRATEGY)

\begin{tabular}{ccc}
\hline Solution & \multicolumn{2}{c}{ Daily Net Cost $(€)$} \\
\cline { 2 - 3 } & Forecasted & Actual \\
\hline Constrained & -156.208573 & -122.114593 \\
Unconstrained & -217.344787 & -165.666463 \\
\hline
\end{tabular}

TABLE VIII

MAXIMUM CURRENT PER CELL FOR EACH BESS AND STRATEGY

\begin{tabular}{ccc}
\hline$n$ & $I_{M}^{n}(\mathrm{PRC})$ & $I_{M}^{n}(\mathrm{UPR})$ \\
\hline 1 & 39.704433 & 57.58299 \\
2 & 28.437849 & 17.274897 \\
3 & 49.340390 & 28.791495 \\
4 & 22.596897 & 14.395748 \\
5 & 40.559986 & 86.374485 \\
6 & 47.366544 & 31.670645 \\
7 & 17.835719 & 13.244088 \\
8 & 10.582127 & 6.334129 \\
9 & 73.519157 & 43.187243 \\
10 & 29.494046 & 17.274897 \\
11 & 23.551881 & 15.547407 \\
12 & 44.643180 & 25.912346 \\
13 & 13.588557 & 8.061619 \\
14 & 42.917748 & 31.670645 \\
15 & 76.374089 & 48.945542 \\
\hline
\end{tabular}

\section{Joint Effects of Forecasting Error and System Capacity}

In this sub-section, the effects of price forecasting error and SG limitations, in terms of the maximum power to be sold or bought by an independent or aggregated BESS, are statistically analyzed.

Our analysis is carried out by evaluating the performance of the independent BESS previously described in IV-B (2V-cells of $\left.C_{10}^{1}=1000 \mathrm{Ah}, S O C_{\min }^{1}=0.3, N_{s}^{1}=200, N_{p}^{1}=1\right)$ over the years of 2014 and 2015, considering different values of the maximum charging or discharging current, specifically $I_{M}^{1}=\left\{0.2\left(I_{10}^{1}\right), 0.4\left(I_{10}^{1}\right), 0.6\left(I_{10}^{1}\right), 0.8\left(I_{10}^{1}\right), I_{10}^{1}\right\}$. The FEP and actual values used in this analysis were those previously estimated and described in IV-A (specifically, those estimated by using the second HWEP database of the period of December 2013 to December 2015).

As stated before in IV-C, a determined BESS $(n)$ integrated with a determined aggregator reduces its charging or discharging power to guarantee the successful operation of the BESS aggregator from the point of view of the DNO; depending on the operating conditions and the SG characteristics, this reduction could be considerable or not. To evaluate the perspective of each BESS incorporated in the aggregator (with high and low reduction of the charging or discharging power), an independent BESS constrained to different values of $I_{M}^{1}$ (specifically between $20 \%$ and $100 \%$ of $I_{10}^{1}$ ) has been investigated.

The most important results related to this experiment are the predicted economic benefit (obtained by evaluating the scheduling obtained from the GA using the FEP), the actual estimated benefit (obtained by evaluating the near-optimal solution suggested by the GA on the actual electricity prices), and the corresponding estimation error (estimated as the subtraction between the forecasted and actual benefit).

The corresponding results obtained from the estimation of all of these variables are presented as histograms of frequency in Figs. 15-17, while the mean and standard deviation values are shown in Tables IX, X, and XI. In Fig. 15, all forecasted 
DNCs are negative to maximize the economic benefit. However, according to the results shown in Fig. 16, when actual values are evaluated, some positive values arise as a consequence of the forecasting error, which represents a total loss of revenue due to the difference between the FEP and the actual values. Similarly, some values of the DNC highly influenced by forecasting error appear as negative estimation errors in Fig. 17 due to the fact that in some days, the revenue estimated using the FEP was higher than that obtained when the actual values were finally evaluated.

In addition, the reduction of the economic benefit could be observed in the first rows of Tables IX and X, in which the mean values of the forecasted DNC are higher than those of the actual DNC due to the fact that we always expect a higher economic benefit than that which occurs when the actual values arise. This fact directly influences the planning problem and the expected revenue during the lifetime of the system and should be considered during the planning evaluation process.

Regarding the SG limits, it is possible to observe how, as the maximum battery current is reduced (to accommodate the BESS power into the SG), the economic benefit and its variability are considerably reduced. In a general sense, those BESSs with low reductions of their charging or discharging capabilities are going to observe reductions of their economic benefits mainly influenced by forecasting error. On the contrary, those BESSs with high reductions of their capabilities are going to observe reductions of their economic benefits mainly influenced by the SG power limits.

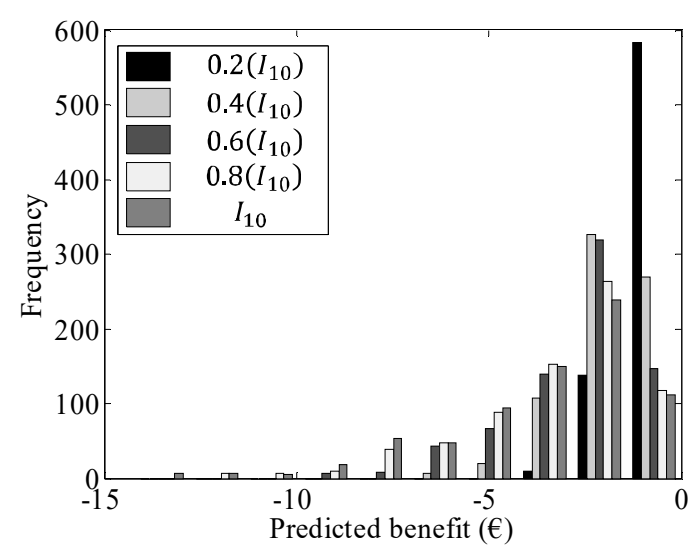

Fig. 15. Histogram of forecasted daily net cost.

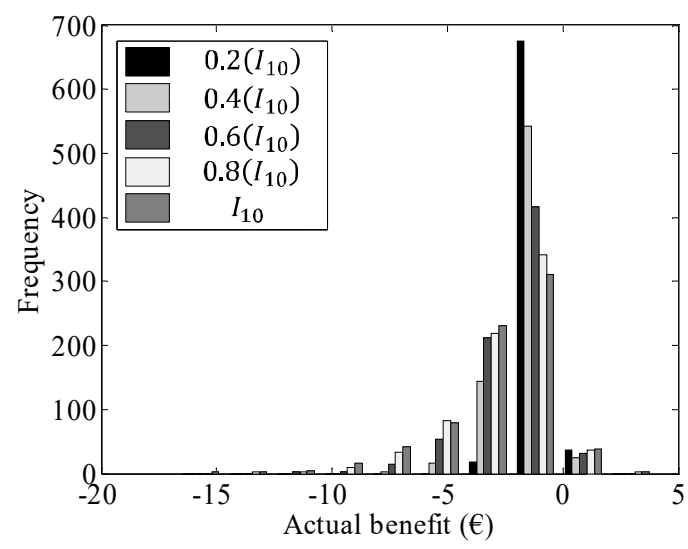

Fig. 16. Histogram of actual daily net cost.

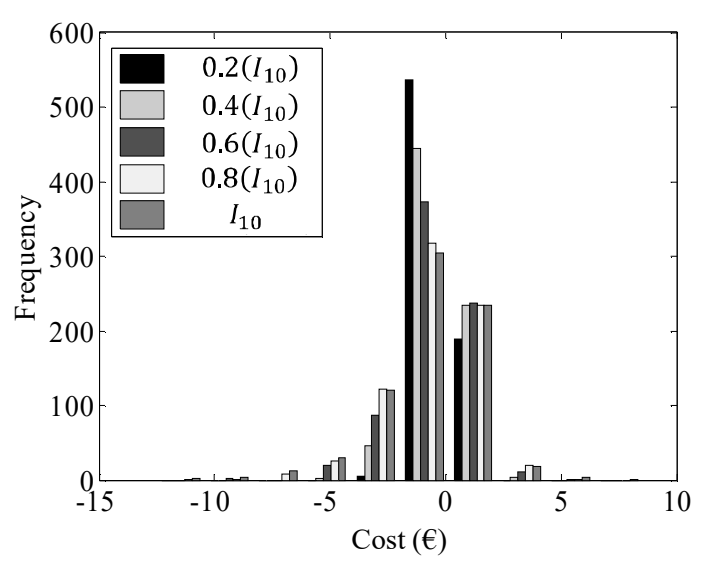

Fig. 17. Histogram of estimation error on daily net cost.

TABLE IX

MEAN AND STANDARD DEVIATION OF FORECASTED DNC

\begin{tabular}{|c|c|c|c|c|c|}
\hline$I_{M}^{1}$ & $0.2\left(I_{10}\right)$ & $0.4\left(I_{10}\right)$ & $0.6\left(I_{10}\right)$ & $0.8\left(I_{10}\right)$ & $I_{10}$ \\
\hline Mean & -1.041 & -1.96896 & -2.75785 & -3.35447 & -3.6694 \\
\hline Dev. & 0.553846 & 1.118292 & 1.683701 & 2.192115 & 2.511537 \\
\hline
\end{tabular}

TABLE X

MEAN AND STANDARD DEVIATION OF ACTUAL DNC

\begin{tabular}{llllll}
\multicolumn{1}{c}{$I_{M}^{1}$} & $0.2\left(I_{10}\right)$ & $0.4\left(I_{10}\right)$ & $0.6\left(I_{10}\right)$ & $0.8\left(I_{10}\right)$ & \multicolumn{1}{c}{$I_{10}$} \\
\hline Mean & -0.8469 & -1.5945 & -2.1973 & -2.62869 & -2.8732 \\
Dev. & 0.559271 & 1.123313 & 1.682101 & 2.133537 & 2.441735 \\
\hline
\end{tabular}

TABLE XI

MEAN AND STANDARD DEVIATION OF ESTIMATION ERROR ON DNC

\begin{tabular}{llcccl}
\hline \multicolumn{1}{c}{$I_{M}^{1}$} & $0.2\left(I_{10}\right)$ & $0.4\left(I_{10}\right)$ & $0.6\left(I_{10}\right)$ & $0.8\left(I_{10}\right)$ & $I_{10}$ \\
\hline Mean & -0.1941 & -0.37446 & -0.56055 & -0.72578 & -0.7962 \\
Dev. & 0.519521 & 1.011225 & 1.497099 & 1.887078 & 2.084716 \\
\hline
\end{tabular}

\section{CONCLUSIONS}

In this paper, a comprehensive methodology for the optimal management of the LAB, operating both independently and as an aggregated system in the RT pricing environments, has been developed and illustrated through some representative examples. The proposed methodology is based on solving the optimization problem using an integer-coded GA that is formulated to minimize the $\mathrm{DNC}$, thereby allowing the incorporation of the non-linear characteristics of the LAB, which are related to voltage-current behavior and gassing phenomena, charge regulation, and the non-linear efficiency of a bidirectional conversion system. Moreover, the technical limitations of the SG imposed by the DNO, which are related to the maximum system capacity, have been taken into account. Hence, the proposed methodology works in a decentralized manner, demonstrating excellent computational efficiency and the ability to provide a feasible and reliable solution from the perspective of the DNO, thus guaranteeing the safe incorporation of the BESS on a massive scale, which is of major importance. Using a representative amount of data from the Spanish electricity market, the effects of forecasting error and the SG limitations on the performance of a BESS aggregator have been evaluated, concluding that the economic benefit of those BESSs with relatively low reductions of their power-transaction capabilities is mainly influenced by 
forecasting error, while the economic benefit of those BESSs with relatively high reductions of their power-transaction capabilities is mainly influenced by the loadability of the SG. In a general sense, the obtained results reveal the importance of considering the specific type of BESS to be installed (in our case, the LAB), all of its associated components (charge controller and power converter) and the optimization technique used to analyze its behavior, the specific competition rules among the BESSs integrated in the aggregator (power reduction by capacity or uniform power reduction), and the mathematical tool used to carry out the FEP (the ARMA model) and its associated error, in the optimal operation of BESSs from an economic perspective. Investments in the expansion and planning of distribution systems directly improve the economic performance of the BESSs integrated with it. Hence, governmental incentives to promote the massive deployment of BESSs should be accompanied by important investments in distribution-system expansion.

\section{REFERENCES}

[1] G. L. Kyriakopoulos, G. Arabatzis, "Electrical energy storage systems in electricity generation: Energy policies, innovative technologies, and regulatory regimes," Renew. Sust. Energ. Rev., vol. 56, pp. 1044-1067, Apr. 2016.

[2] R. Dufo-López, and J. L. Bernal-Agustín, "Techno-economic analysis of grid-connected battery storage," Energ. Convers. Manage., vol. 91, pp. 394-404, Feb. 2015.

[3] R. Dufo-López, "Optimisation of size and control of grid-connected storage under real time electricity pricing conditions," Appl. Energ., vol. 140, pp. 395-408, Feb. 2015.

[4] Available: http://energy.gov/savings/self-generation-incentive-program [Accessed: 13-July.-2016].

[5] H. Khani and M. R. D. Zadeh, "Online adaptive real-time optimal dispatch of privately owned energy storage systems using public-domain electricity market prices," IEEE Trans. Power Syst., vol. 30, pp. 930938, Mar. 2015.

[6] A. Damiano, G. Gatto, I. Marongiu, M. Porru, and A. Serpi, "Real-time control strategy of energy storage systems for renewable energy sources exploitation," IEEE Trans. Sustain. Energy, vol. 5, pp. 567-576, Apr. 2014.

[7] Y. Wang, X. Lin, and M. Pedram, "Adaptive control for energy storage systems in households with photovoltaic modules," IEEE Trans. Smart Grid, vol. 5, pp. 992-1001, Mar. 2014.

[8] Y. Wang, X. Lin, and M. Pedram, "A near-optimal model-based control algorithm for households equipped with residential photovoltaic power generation and energy storage systems," IEEE Trans. Sustain. Energy, vol. 7, pp. 77-86, Jan. 2016.

[9] J. Li, Z. Wu, S. Zhou, H. Fu, and X.-P. Zhang, "Aggregator service for PV and battery energy storage systems of residential building," CSEE Journal of Power and Energy Systems, vol. 1, pp. 3-11, Dec. 2015.

[10] K. Meng, Z. Y. Dong, and Z. Xu, "Cooperation-driven distributed model predictive control for energy storage systems," IEEE Trans. Smart Grid, vol. 6, pp. 2583-2585, Nov. 2015.

[11] S. Sun, and M. Dong, "Distributed real-time power balancing in renewable-integrated power grids with storage and flexible loads," IEEE Trans. Smart Grid, vol. PP, pp. 1, July 2015.

[12] Y. Yoon, Y.-H. Kim, "Effective scheduling of residential energy storage systems under dynamic pricing," Renew. Energ., vol. 87, pp. 936-945, Mar. 2016.

[13] L. Zhang, and Y. Li, "Optimal energy management of wind-battery hybrid power system with two-scale dynamic programming," IEEE Trans. Sustain. Energy, vol. 4, pp. 765-773, July 2013.
[14] M. Y. Nguyen, D. H. Nguyen, and Y. T. Yoon, "A new battery energy storage charging/discharging scheme for wind power producers in realtime markets," Energies, vol. 5, pp. 5439-5452, Dec. 2012.

[15] E. Telaretti, M. Ippolito, and L. Dusonchet, "A simple operating strategy of small-scale battery energy storages for energy arbitrage under dynamic pricing tariffs," Energies, vol. 9, pp. 1-20, Dec. 2016.

[16] H. Sugihara, K. Yokoyama, O. Saeki, K. Tsuji, and T. Funaki, "Economic and efficient voltage management using customer-owned energy storage systems in a distribution network with high penetration of photovoltaic systems," IEEE Trans. Power Syst., vol. 28, pp. 102111, Feb. 2013.

[17] R. Mallol-Poyato, S. Salcedo-Sanz, S. Jiménez-Fernández, P. DíazVillar, "Optimal discharge scheduling of energy storage systems in microgrids based on hyper-heuristics," Renew. Energ., vol. 83, pp. 1324, Nov. 2015.

[18] L. Siemer, F. Schöpfer, D. Kleinhans, "Cost-optimal operation of energy storage units: benefits of a problem-specific approach," Journal of Energy Storage, vol. 6, pp. 11-21, May 2016.

[19] W. Tushar, B. Chai, C. Yuen, S. Huang, D. B. Smith, H. V. Poor, and Z. Yang, "Energy storage sharing in smart grid: A modified auctionbased approach," IEEE Trans. Smart Grid, vol. 7, pp. 1462-1475, May 2016.

[20] D. Stimoniaris, D. Tsiamitros, and E. Dialynas, "Improved energy storage management and $\mathrm{PV}$-active power control infrastructure and strategies for microgrids," IEEE Trans. Power Syst., vol. 31, pp. 813820, Jan. 2016.

[21] E. Reihani, S. Sepasi, L. R. Roose, M. Matsuura, "Energy management at the distribution grid using a battery energy storage system (BESS)," Int. J. Elec. Power, vol. 77, pp. 337-344, May 2016.

[22] B. B. McKeon, J. Furukawa, and S. Fenstermacher, "Advanced leadacid batteries and the development of grid-scale energy storage systems," Proc. IEEE, vol. 102, pp. 951-963, June 2014.

[23] Available: http://www.energystorageexchange.org/ [Accessed: 13-July2016].

[24] M. Rosenblatt, "Remarks on a multivariate transformation," Ann. Math. Statist., vol. 23, pp. 470-472, 1952.

[25] A. Barbiero, "A general discretization procedure for reliability computation in complex stress-strength models," Math. Comput. Simulat., vol. 82, pp. 1667-1676, May 2012.

[26] R. Weron, "Electricity price forecasting: A review of the state-of-the-art with a look into the future," Int. J. Forecasting, vol. 30, pp. 1030-1081, Oct.-Dec. 2014.

[27] G. Schwarz, "Estimating the dimension of a model," Ann. Statist., vol. 6, pp. 461-464, Mar. 1978.

[28] H. Akaike, "A new look at the statistical model identification," IEEE Trans. Autom. Control, vol. 19, pp. 716-723, Dec. 1974.

[29] G. M. Ljung, G. E. P. Box, "On a measure of lack of fit in time series models," Biometrika, vol. 65, pp. 297-303, 1978.

[30] J. Schiffer, D. U. Sauer, H. Bindner, T. Cronin, P. Lundsager, R. Kaiser, "Model prediction for ranking lead-acid batteries according to expected lifetime in renewable energy systems and autonomous power-supply systems," J. Power Sources, vol. 168, pp. 66-78, May 2007.

[31] J. B. Copetti, E. Lorenzo, and F. Chenlo, "A general battery model for PV system simulation,” Prog. Photovolt: Res. Appl., vol. 1, pp. 283-292, Oct. 1993.

[32] B. Hahn, Fortran 90 for scientists and engineers, Elsevier, 1994.

[33] G. A. Rampinelli, A. Krenzinger, F. Chenlo, "Mathematical models for efficiency of inverters used in grid connected photovoltaic systems," Renew. Sust. Energ. Rev., vol. 34, pp. 578-587, June 2014.

[34] V. Svoboda, H. Wenzl, R. Kaiser, A. Jossen, I. Baring-Gould, J. Manwell, P. Lundsager, H. Bindner, T. Cronin, P. Nørgård, A. Ruddell, A. Perujo, K. Douglas, C. Rodrigues, A. Joyce, S. Tselepis, N. van der Borg, F. Nieuwenhout, N. Wilmot, F. Mattera, D. U. Sauer, "Operating conditions of batteries in off-grid renewable energy systems," Sol. Energy, vol. 81, pp. 1409-1425, Nov. 2007.

[35] Available: http://www.ree.es/en [Accessed: 13-July-2016]. 


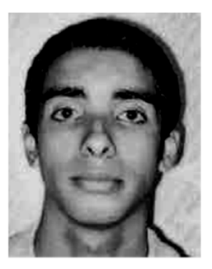

Juan M. Lujano-Rojas received his Ph.D. degree from the University of Zaragoza, Spain, in 2012. In 2013, he joined the University of Beira Interior (UBI), Covilha, Portugal, as a researcher in the EU-funded FP7 project SiNGULAR. Currently, he is a post-doctoral fellow at INESC-ID/IST-UL and UBI.

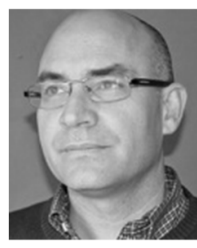

Rodolfo Dufo-López received the B.S., M.S. and Ph.D degree from University of Zaragoza, Spain, in 1994, 2001 and 2007, respectively. In 2004, he joined the University of Zaragoza, where he is currently a Professor of the Department of Electrical Engineering. He has published more than 50 journal papers and conference proceedings. His research interests include renewable energy, distribution systems, smart grid, power quality, generation and demand side management, and power systems analysis.

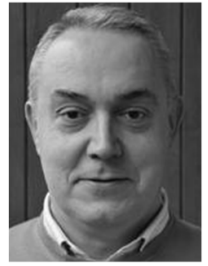

José L. Bernal-Agustín (M'04) received his Ph.D. degree from the University of Zaragoza, Spain, in 1998 In 1991, he joined the University of Zaragoza, where he is currently a Professor of the Department of Electrical Engineering. He has published more than 70 journal papers and conference proceedings. His research interests include applications of evolutionary algorithms in electrical power systems, distribution systems, electric markets, renewable energy and smart grids.

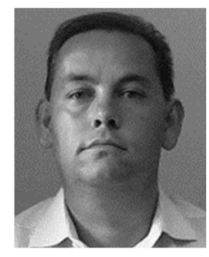

João P. S. Catalão (M'04-SM'12) received the M.Sc. degree from the Instituto Superior Técnico (IST), Lisbon, Portugal, in 2003, and the Ph.D. degree and Habilitation for Full Professor ("Agregaçao") from the University of Beira Interior (UBI), Covilha, Portugal, in 2007 and 2013, respectively.

Currently, he is a Professor at the Faculty of Engineering of the University of Porto (FEUP), Porto, Portugal, and Researcher at INESC TEC, INESC-ID/IST-UL, and C-MAST/UBI. He was the Primary Coordinator of the EU-funded FP7 project SiNGULAR ("Smart and Sustainable Insular Electricity Grids Under LargeScale Renewable Integration"), a 5.2-million-euro project involving 11 industry partners. He has authored or coauthored more than 470 publications, including 155 journal papers, 281 conference proceedings papers, 23 book chapters, and 11 technical reports, with an $h$-index of 27 and over 3000 citations (according to Google Scholar), having supervised more than 45 postdocs, Ph.D. and M.Sc. students. He is the Editor of the books entitled Electric Power Systems: Advanced Forecasting Techniques and Optimal Generation Scheduling and Smart and Sustainable Power Systems: Operations, Planning and Economics of Insular Electricity Grids (Boca Raton, FL, USA: CRC Press, 2012 and 2015, respectively). His research interests include power system operations and planning, hydro and thermal scheduling, wind and price forecasting, distributed renewable generation, demand response and smart grids.

Prof. Catalão is an Editor of the IEEE TRANSACTIONS ON SMART GRID, an Editor of the IEEE TRANSACTIONS ON SUSTAINABLE ENERGY, and an Associate Editor of the IET Renewable Power Generation. He was the Guest Editor-in-Chief for the Special Section on "Real-Time Demand Response" of the IEEE TRANSACTIONS ON SMART GRID, published in December 2012, and the Guest Editor-in-Chief for the Special Section on "Reserve and Flexibility for Handling Variability and Uncertainty of Renewable Generation" of the IEEE TRANSACTIONS ON SUSTAINABLE ENERGY, published in April 2016. He was the recipient of the 2011 Scientific Merit Award UBI-FE/Santander Universities and the 2012 Scientific Award UTL/Santander Totta. Also, he has won 4 Best Paper Awards at IEEE Conferences. 